\title{
Exploration on Open-Mode Experimental Teaching in Agricultural Electrification and Automation Specialty
}

\author{
Lili Gao and Xingru Lu ${ }^{b}$ \\ School of Engineering and Technology, Jilin Agricultural University, Changchun, China \\ a568492564@qq.com, ${ }^{b} 1029645185 @ q q . c o m$
}

Keywords: Applied; Agricultural electrification and automation; Open-mode experimental teaching; Experiment teaching

\begin{abstract}
Experiment teaching plays an important role that can't be ignored during the process of applied undergraduates' talents training. Based on characteristics and cultivate objective of specialization itself in agricultural electrification and automation in the course of experimental teaching reform, this paper presents open-mode experimental teaching of agricultural electrification and automation specialty. Through open-platform experimental teaching, open experimental teaching content, diverse teaching means, the guiding of the teaching process and the reasonability of teaching effect evaluation of agricultural electrification and automation specialty, it states open-mode experimental teaching in detail.
\end{abstract}

\section{Introduction}

Experiment teaching is an important procedure of higher school teaching and it is also an indispensable part in the course of talents educating. Experiment teaching plays a special role as to develop students' innovative consciousness, practice ability, ability to analyze and solve problems[1]. Profession experiment teaching combines students' professional knowledge as mentioned in carry out experimental activities in this paper, which not only keeps students firmly in control and use this knowledge correctly, but also gets the students' various abilities and comprehensive qualities to get the exercise.

Training objective of agricultural electrification and automation specialty is to provide the students advanced technicians within solid theory foundation, combination of science with technology, all round qualities, practical ability and high innovative consciousness for society. Therefore, training of professional skills is an important aspect of specialized training goal to agricultural electrification and automation specialty. Training of students' professional skills primarily are done through practice teaching links of experiment, production practice, curriculum design and graduate project. The realization of this goal needs facilities and models which are matching to experiment teaching.

In recent years, universities increase investment of laboratory construction gradually, the experimental teaching equipment has been updated greatly, experiment teaching environment have changed measurably, the understanding of experimental teaching function has improved qualitatively, the role and importance of experimental teaching have prominent gradually, laboratory construction and experimental teaching reformation have shown a significant progress. Based on the important role and special role of experimental teaching in the cultivation of application-oriented undergraduate talent, efforts to reform the experimental teaching mode of agricultural electrification and automation major, it is of great crucial to probe the fresh pattern of experimental teaching of developing the students' innovative abilities. Exploring open experiment teaching mode is to accomplish this, which makes experiment teaching more in line with the requirement of cultivating talented personnel of high qualities who meet the new age[2,3,4].

\section{The Concept of Open Experiment Teaching}

Open experiment teaching takes experiment as a kind of innovative practical activity, which promotes students to choose freely, to design experimental project and to carry out synthetic, 
design ability and research experiment autonomously, which is beneficial to make full use of laboratory equipment resources and mobilize students to practice actively, which make students give the rein to the creative thinking and improve the ability of practical skill in practice, so as to achieve the goal of the quality education.

Open-mode experimental teaching makes students pull back from enclosed learning environment, gives them a open and free learning environment, which is beneficial students to improve both the thinking dependently and operation skills abilities and increase the future job seeking ability, which make students accord to their interests and plan to go into work to freely choice experiment[5]. Open-mode experimental teaching is able to adapt different levels and capacities personality requirements of students, which improves students' experimental interest and fully arouse students' subjective initiative[6].

Open experiment teaching not only opens experimental time, but also opens experimental equipment. The opening can effectively relieve a tense situation of the present experimental resources in some Universities, which solve the phenomenon of short of instruction equipment and lab in peak, large quantity of empty instrument and laboratory in trough, which improves the utilization of the present instruction equipment and lab. At the same time, it also can promote university to introduce advanced laboratory equipment and to expand infrastructure construction. Open-mode experimental teaching is developing trend of experiment teaching, which can correspond relation between teaching and learning during the experimental teaching well.

\section{Open-Mode Experimental Teaching in Agricultural Electrification and Automation Specialty}

Many universities are all trying to start laboratory opening work in Chinese institution of higher learning and gains a lot of valuable experiences. During the study, we can learn from other professional valuable experiences but never totally copy them[7].

Agricultural electrification and automation specialty is a professional and practical comprehensive disciplines. In order for experimental teaching sector of agricultural electrification and automation specialty to be better able to adapt the need of cultivating innovative and complex talents, it has to inherit traditional advantages in practice teaching and at the same time vigorously promote open-mode experimental teaching. Combining with the subject characteristics subject of agricultural electrification and automation specialty, departing from protruding to cultivate students' creative ability and solving practical engineering problems ability with hands. Based on choice of experimental teaching platform, experimental teaching methods, experimental teaching means, experimental teaching process and experimental teaching evaluation, building open-mode experimental teaching in agricultural electrification and automation specialty.

Open experimental teaching platform. Traditional experimental teaching mode can conventional experiment be conducted under the circumstance of having student, teacher and experiment content. Open experimental teaching platform is composed of software and hardware. Software is based on network information technology, the premise is to build up a experiment teaching management platform, information platform and experiment teaching database of university campus network, these resources are necessary foundation of open experimental teaching platform. Network experimental teaching platform mainly consists of experimental teaching resources, experimental teaching demo video or network course, description of instrument and equipment, testing system on line and simulation experiment. Its function is to Secondary student preparing experimental, study the purpose, principle and content of the experiment. It also includes experimental on-line booking system, experimental subject management, information inquiry, statistical scores and experiment assessing question bank. Hardware is based on the floor experimental equipment. Open experimental teaching platform is composed of Nine LABS-experiment for automatic control theory, electrical laboratory, automatic technology laboratory, fundamentals of mono-chip computers laboratory, embedded laboratory, process control laboratory, programmable logic control laboratory, electronic laboratory, electrical drive laboratory. In order to make rational use of limited funds and venues, in order for the soft and hard resources to be shared and comprehensive utilization of instrument and equipment to achieve the biggest benefit 
at a minimum investment, so the platform is always open On the whole.

Taking electronic experiment as an example, it comes to multiple instruments- oscilloscope, voltage source, signal generator and so on during the course of the experiment, function of the use of instruments of a direct both impact on experiment effect and also affect understanding of knowledge. In order for the students to fully understand the actual effect of the circuit before the experimental course begins and in this course, it makes first students understand use of equipment and simulation experiments of circuits on the online experiment platform and then do online booking to exercise experiment. Students are very interested in learning control elements from the perceptual and the rational by understanding, the acquisition of knowledge significantly go deep.

Open experiment teaching content that its experiment content is single and old. Traditional experimental teaching mode and it is often more of replication experiment. Writing experimental principle and procedure, even certain experimental results all on the experiment report in many cases, which is bad for playing better to students' subjective initiative and training students with creative ability and the improvement of comprehensive quality, and yet open experimental teaching think much of experiment content expanding from "replication" to "general" and "design". Experiment content need to ladder-type and design.

The first ladder is basic teaching experiment. It is predominantly replication experiment and can cultivate students' basic skill of experiment, in the course of the circuit, digital electronic technology, simulation electronic, electrical machinery experiment and so on which emphasize students' basic practical skill in basic courses.

The second ladder is professional skills experiment. The comprehensive experiment courses of focusing on professional skills are include of principle of single chip computer, programmable logic controller, principle of automatic control, process control system and so on, which focus on cultivating students' abilities that learned the practical application of the theory they had learned in the classroom. Open experiment sites are not only in school, more to go into the factory, which increase students' internship opportunities and developing skills and expertise in real application. Location places of common internship of students are car factories and waste-water treatment plants where common learning is advanced in automation major, but it has its limitations, colleges and schools are also actively preparing for own bases for production and practice.

The third ladder is designing experiments for the interest. Experimental project is loosely defined, which can supply enough space for students to build own problem frames. Learner can try to explore different solutions and also can aim at a solution to ask for different interpreting argument, only in this way can trigger thoughts and activate the inspiration. For example, to expand teachers' researches and practical subjects which attract interested students and then enter the subject research, which can enlarge the students' view while improving students' professional skills. It's expanded enormously the students' knowledge and is beneficial for students' employment.

Finally, taking every kind of competition as an opportunity, organizing planned professional electronic design competition, single chip computer innovation design competition, national undergraduate electronic design contest and robotics competition, etc, bringing practice teaching in class and extracurricular scientific and technological practice closer together. Unnecessary extracurricular science and technology activities make into the necessary link of practice teaching, which become an important way of cultivating students practical skills.

The diversification of teaching means. Open-mode experimental teaching utilizes the difference of learning process to adjust the intelligence, ability, interest and specialty of the individual student, which supply diversity and independent learning style for students with different developmental characteristics, which make every student get substantial gains to realize maximum of the effect of experiment teaching and provide an opportunity for the development of each student, thus realizing the purpose of open experiment teaching.

People's practical ability and innovation ability are the level, therefore the cultivation of practical ability are also the level. Experiment teaching contents themselves have the level and the integrity to realize though experiment, curriculum design, graduation project and academic competition of basic, profession, design and research. Therefore, open experiment teaching means can't 
unchangeable and have diversity.

The guiding of the teaching process. Open experimental teaching require student improve self-learning ability and require teacher change the focus of teaching. Teachers should change from teaching experimental procedure and test results to lead the students to complete the related experiment project, help student analysis, solve the related problems in the experiment, aptitude, stimulate students' learning interests, make students switch from passive learning to autonomous learning. But students often encounter all kinds of difficulty from cognition, skills or emotion in the autonomous learning activity, if teacher can't provide support for student, then learning process is bound to end. In spite of students' learning activities is a process of internalization of the subject, but this process should not be blind and unordered, otherwise, the efficiency of learning will be reduced and be going to take some detours that often defeats its own purpose. Therefore, studying the characteristics of student learning activities, combining these features to guide student to learn in a planned and purposeful way, it is important in open experiment teaching.

The characteristics of open experimental teaching mode are that students learn by themselves, teachers become designer, organizer and director for students' knowledge learning and ability training. Students apply what they have acquired knowledge to select or raise experiment items, design experimental projects, manage laboratory instrument, install and set up, trouble shooting, observer phenomenon, analysis data and reach a conclusion in open experimental teaching process. The process that students find problems to solve problems independently is the process of students' ability obtaining exercise directly, is also a experience gained process. Experimental instructor should timely direct problems arising from open experiment for students to solve independently in order to improve their abilities of solving practical problems.

The rationality of teaching effect evaluation. Teaching evaluation has guiding function, open-mode experimental teaching can't adopt the original evaluation system. It can no longer be a pass test and should be more scientific objectives. Experiments adopt different evaluation methods at different levels, That is the evaluation should be diversified which should be able to evaluate what students have learned in the process of experiment. Just focusing on the results will result in the students experimented for the experiment, which make experiment lose the proper sense. Making an all-round assessment on students' abilities which include practical abilities, creativity abilities, design abilities and the abilities of posing problems in experiment. In the open experimental teaching system, evaluation of teachers' experimental teaching quality should also be open, using online teaching evaluation by students. Evaluation results as an indicator of annual assessment which motivate guide teachers improve constantly experiment teaching methods.

\section{Conclusions}

Open experiment teaching is not simple revolution of experiment teaching management style but the whole reformation of experiment teaching system. While emphasizing the form, need to notice the necessity of culture construction. Opening experimental platform is the cooperation between teachers and students, which needs to have an atmosphere of inner culture and learning. Many factors are involved, the lab managers' and teachers' education ideas needs to be a big shift in the process, experimental teaching contents, teaching methods, teaching meansand experimental teaching evaluations are all going to change. Build a well-functioning open experimental teaching system in agricultural electrification and automation specialty is a complex systematic project, open experiment teaching is the trend of experimental teaching reform.

\section{Acknowledgments}

This research is supported by Jilin Provincial Association of Higher Education under grant number JGJX2016D37 and school-based specific subject of Jilin Agricultural University in 2016. 


\section{References}

[1] Y.X.Chen: Research and practice of innovative talent cultivation based on open experimental teaching mode, Journal of Jiamusi Education Institute, No.3 (2014) p.176-177. (In Chinese)

[2] G.Q. Gai and G.L. Song:Research and practice of open experimental teaching management mode, Hei long jiang Researches on Higher Education, No.5 (2009) p.162-164. (In Chinese)

[3] S.L. Wang:To establish the restriction factors and countermeasures of the long - term mechanism of laboratory opening, Research and Exploration in Laboratory, No.5 (2007) p.106-109. (In Chinese)

[4] H. Li:The discussion of open experimental teaching in colleges and universities, Experimental Technology and Management, No.5 (2003) p.172-174. (In Chinese)

[5] X.L,Wang:Agriculture Electric and Automatic Specialty of Construction and Development Discussion, Scientific and Technical Information, vol.29 (2010) p.169-170. (In Chinese)

[6] Z.L. Piao and T.Y. Xu, G.K. Sun: Reflection on the fostering orientation of postgraduates majoring in agricultural electrification and automation at agricultural colleges and universities, Transactions of the CSAE, No.5 (2005) p.183-185. (In Chinese)

[7] A.G. Tan: Multi-level open electrical and electronic experiment teaching mode, Research and Exploration in Laboratory, No.8 (2010) p.127-129. (In Chinese) 